in a group of dialysed patients. It would also explain why the patients of Seedat (1969), with apparent potassium deficits ranging from 20 to $35 \%$, produced no symptoms of potassium depletion such as dysfunction of many organs which would be expected at these levels (Black, 1967).

Seedat (1969) also found that the exchangeable potassium decreased as the duration of dialysis treatment increased but this was not observed when total body potassium was measured (Morgan et al., 1970; Boddy et al., 1972a). However, it could be the exchangeable fraction of total body potassium that alone diminishes with increasing duration of dialysis.

We elected to study non-dialysed patients, in the first instance, rather than dialysed patients because of the transient disequilibrium induced by the dialysis procedure and because of practical difficulties in measuring up to 64 hours without the intervention of dialysis when the patients were receiving twice-weekly dialyses. Despite these difficulties the study is being extended to dialysed patients.

We wish to thank Professor H. W. Wilson for his interest and encouragement and the Cyclotron Unit, Hammersmith Hospital, and the Radiochemical Centre, Amersham, for their co-operation in deliveries of ${ }^{43} \mathrm{~K}$. This study was supported in part by a grant from the Scottish Hospital Endowments Research Trust which is gratefully acknowledged.

Requests for reprints should be sent to Dr. Keith Boddy, Scottish Research Reactor Centre, East Kilbride, Glasgow.

\section{References}

Black, D. A. K. (1967). Essentials of Fluid Balance, p. 86, Oxford, Blackwell Scientific.

Boddy, K. (1967). British fournal of Radiology, 40, 631.

Boddy, K., King, P. C., Tothill, P., and Strong, J. A. (1971). Physics in Medicine and Biology, 16, 275.

Boddy, K., King, P. C., Hume, R., and Weyers, E. (1972b). Fournal of Clinical Pathology. In press.

Boddy, K., et al. (1972a). In preparation.

Corsa, L., Olney, J. M., Steenburg, R. W., Ball, M. R., and Moore, F. D. (1950). Fournal of Clinical Investigation, 29, 1280.

de Deuxchaisnes, C. N., Collet, R. A., Busset, R., and Mach, R. S. (1961) Lancet, $1,681$.

Moore, F. D., et al. (1954). Metabolism, 3, 334.

Morgan, A. G., Burkinshaw, L., Robinson, P. J. A., and Rosen, S. M. (1970). British Medical fournal, 1, 779.

Remenchik, A. P., and Miller, C. E. (1962). In Proceedings of the Symposium on Whole-Body Counting, p. 331 . Vienna, International Atomic En Whole-Body

Seedat, Y. K. (1969). British Medical fournal, 2, 344.

Surveyor, I., and Hughes, D. (1968). Fournal of Laboratory and Clinical Medicine, 71, 464.

Talso, P. J., Miller, C. E., Carballo, A. J., and Vasquez, I. (1960). Metabolism, 9, 456 .

\title{
Mortality after Vagotomy and Pyloroplasty for Duodenal Ulcer
}

\author{
S. J. A. POWIS, J. J. PRICE, D. M. MORRISSEY
}

British Medical fournal, 1972, 1, 142-144

\section{Method}

Summary

A retrospective survey of 4,026 patients having truncal vagotomy and pyloroplasty for duodenal ulceration showed a mortality rate of $1.4 \%$ (55 patients). On analysis the commonest causes of death were found to be bronchopneumonia 37\% (18 patients) and sepsis 20\% (10 patients). More than half of the deaths occurred in patients aged over 50.

\section{Introduction}

Vagotomy and gastric drainage has recently become widely practised as a definitive procedure for the treatment of duodenal ulceration. This is because of its satisfactory success rate (Mead, 1967; Whittaker et al., 1967; Eisenberg et al., 1969; Savage and McVay, 1970; Small and Jahadi, 1970), low operative mortality, postoperative mortality, and morbidity. The incidence of such postoperative symptoms as are reported after partial gastrectomy is also much lower. Many series, frequently from gastroenterological units, mention the mortality rate, often compared with partial gastrectomy (Goligher et al., 1968a, 1968b), but there are no reports of the mortality in large series performed by many surgeons in many centres. Only such surveys which include gastroenterological units, teaching and non-teaching, as well as large and small hospitals can give an accurate assessment of the mortality of the procedure.

\section{Queen Elizabeth Hospital, Birmingham B15 2TH}

S. J. A. POWIS, F.R.c.s., Senior Surgical Registrar (Present address: Royal Hospital, Wolverhampton)

J. J. PRICE, M.R.C.P., F.R.c.s., Surgical Registrar (Present address : Roval Infirmary, Bradford)

D. M. MORRISSEY, M.CH., F.R.c.s., Consultant Surgeon

The Birmingham Regional Hospital Board computer service provided information about 4,026 patients who had had an abdominal truncal vagotomy and pyloroplasty for duodenal ulceration in the five-year period 1965-9, 203 of which were performed as an emergency for perforation. The number performed for haemorrhage cannot be determined as the International Statistical Classification does not differentiate between duodenal ulcers with and without bleeding. Included in the survey are details from 18 hospitals, 16 being regional hospitals, which include five postgraduate surgical training centres, and two being in the United Birmingham Hospitals teaching group.

The clinical notes of the 55 patients dying during the hospital postoperative period were requested and those of all but six, which were not available, were examined. Details of necropsy findings were also available in 35 instances.

\section{Results}

In the five-year period 1965-9 4,026 vagotomy and pyloroplasty operations were performed for duodenal ulceration in those hospitals of the Birmingham Regional Hospital Board served by computer facilities. Eighteen hospitals and 87 consu'tant surgeons were involved. The number of surgeons performing the operation is not known exactly, but must have exceeded the number of consultants concerned, as many registrars, senior registrars, and lecturers operate in the region.

In this five-year period 55 hospital deaths occurred after vagotomy and pyloroplasty. The clinical records of only 49 of these cases were available. Necropsies were carried out in 35 of the 49, providing accurate details of the cause of death. Of the remaining 14, examination of the notes showed good evidence of accurate diagnosis in 13.

Of the 49 patients, 42 were male and seven female, with an 
average age of 58.7 (range 17-88) years. The average age of all patients operated on was 46.9 (range $3-89$ ) years. The mean age of patients who died was thus 11.8 years older than that age of all those operated on (see Chart). Nineteen of the operations were performed as emergency procedures, 13 for bleeding and 6 for perforated duodenal ulcers. The mortality rate in this series for vagotomy and pyloroplasty for perforated ulcer is therefore $2.9 \%$ ( 6 of 203 patients). The causes of death are shown in the Table.

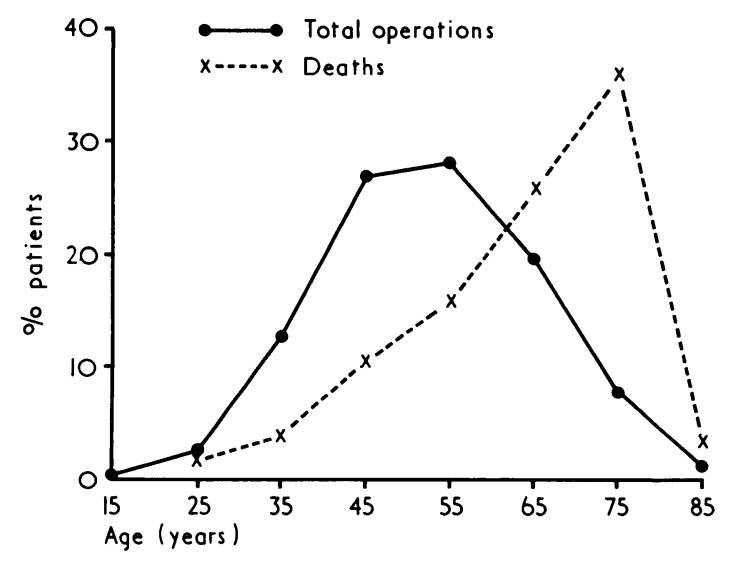

Age of all patients at time of operation and age at death in the 49 fatal cases

Cause of Death in 49 Cases

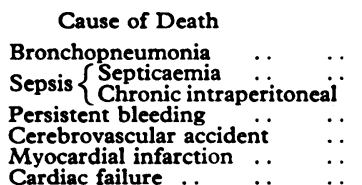

\begin{tabular}{c|} 
No. \\
18 \\
3 \\
7 \\
4 \\
4 \\
3 \\
2
\end{tabular}

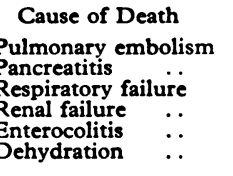

Of the 18 patients who died from bronchopneumonia, 15 had a history of chronic bronchitis. Eight had had emergency operations, six for bleeding and two for perforation. The average age in this group was 68.8 years. Not surprisingly it is shown that increasing age increases the risks of vagotomy and pyloroplasty, more than $50 \%$ of those dying being over 50 years of age (see Chart).

The second commonest cause of death, sepsis, accounted for just over $20 \%$. Three of the 10 patients suffered from septicaemia, one following a perforated duodenal ulcer, the other two due to leakage from the pyloroplasty site. The remaining seven suffered from chronic intraperitoneal sepsis associated with subphrenic and intraperitoneal abscesses, in three due to leakage from the pyloroplasty and in four due to perforation of the oesophagus. Oesophageal perforation accounted for $7 \%$ of the deaths in this series (4 of 55 deaths).

Persistent bleeding occurred in four patients. On three of these emergency operation had been performed for gastrointestinal bleeding, which was not controlled by underrunning the ulcer and performing pyloroplasty and vagotomy. In one case massive intraperitoneal bleeding occurred after elective surgery for duodenal ulceration, but despite a second laparotomy the patient died.

Of the four patients who died from cerebrovascular accident three were aged patients $(66,67$, and 72 years) with preoperative evidence of widespread atherosclerosis. One patient aged 34 suffered a subarachnoid haemorrhage some days postoperatively.

Both patients dying from pulmonary embolism had an antemortem diagnosis of deep venous thrombosis. Anticoagulation was not undertaken in either case because one patient was 73 years old and the other was operated on for massive haemorrhage.

\section{Discussion}

Other surveys of morbidity and mortality after pyloroplasty and vagotomy abound in the literature, but invariably they consider the results of specialist centres and comparatively small numbers of patients. This survey was undertaken to establish the mortality in a large number of patients subjected to the operation in many centres, including major gastroenterological centres and smaller hospitals without such services, performed by many surgeons of all grades.

Fifty-five patients died in a five-year period, during whi-h 4,026 vagotomies and pyloroplasties were performed. This mortality rate of $1.4 \%$ is lower than those in several reported series, but is higher than in some consisting of only a few patients in major gastroenterological units. The notes of 49 of these patients were closely studied to establish the cause of death and to expose any predisposing factors there may have been.

The commonest single cause of death was bronchopneumonia, usually a terminal event after a steady downhill course. This occurred predominantly in the older patients, average age 68.8 (range 50-75) years. Eight of the 18 operations performed on those dying from bronchopneumonia had to be undertaken because of either bleeding (six patients) or perforation (two patients). In several of these cases operations had previously been considered, but because of severe bronchitis and emphysema, ulcer symptoms had been treated medically until the emergency arose. Four of the remaining 10 patients had initially been considered unsuitable for surgical treatment, but severe exacerbations of symptoms, uncontrolled by medical treatment, had made surgery mandatory although it was accepted that a high mortality could be anticipated.

Of the 10 patients who died from sepsis, three had septicaemia. In one this was not surprising as she had a vagotomy and pyloroplasty for duodenal ulceration while awaiting renal transplantation for chronic renal failure. The other two patients succumbed to septicaemia following leakage from the pyloroplasty. Seven patients died of chronic subphrenic or intraperitoneal sepsis, three due to leakage from the pyloroplasty, and four after oesophageal perforation during vagotomy. In two of the latter the oesophageal leak was recognized at the time of operation, and the defects were closed, while in the remaining two the perforation was suspected postoperatively and confirmed at subsequent laparotomy. Oesophageal perforation occurs in $0.8 \%$ of vagotomies (Price et al., 1972), but if recognized and treated at the time of operation, mortality is lower than if the perforation is diagnosed postoperatively. Nine of the deaths in this group were due to an error of surgical technique and therefore theoretically preventable.

Persistent haemorrhage accounted for four deaths, in three of which bleeding occurred into the gastrointestinal tract. In these cases the operation had been performed as an emergency for massive haemorrhage from a duodenal ulcer. Consequently, these three patients were subjected to surgery after receiving large transfusions, which continued during operation and the postoperative period. These transfusions may have interfered with blood coagulation, though analysis of clotting factors was not available in any case. If such investigations had been performed, and the appropriate treatment undertaken, some of these patients might have survived. The other patient who died from haemorrhage had a large intraperitoneal haemorrhage immediately after operation, and despite a second laparotomy, when many pints of blood were removed from the peritoneal cavity, he died during this procedure. Subsequent necropsy failed to demonstrate with certainty the origin of the intraperitoneal bleeding.

The remaining causes of death are inherent comolications of major abdominal surgery, especially in older patients (see Table). It is interesting that only one patient in this series died from enterocolitis, which was the commonest cause of death in a large series of patients subjected to partial gastrectomy (Dawson-Edwards and Morrissey, 1954). This probably 
reflects the increased efficiency of parenteral fluid administration in recent years.

Though the mortality in this series compares favourably with most of the published works, some of the deaths could have been prevented by more rigorous patient selection, especially in the older age group, and by achieving the unlikely state of technical perfection.

We would like to thank members of the West Midlands Surgical Society who allowed the notes of their patients to be studied. The co-operation of Mrs. Wall, at the statistics department, Birmingham Regional Hospital Board, is also appreciated.

Requests for reprints should be sent to Mr. D. M. Morrissey, Queen Elizabeth Hospital, Birmingham B15 2TH.

\section{References}

Dawson-Edwards, P., and Morrissey, D. M. (1954). British fournal of Surgery, 42, 643 .

Eisenberg, M. M., Woodward, E. R., Carson, T. J., and Dragstedt, L. R. (1969). Annals of Surgery, 170, 317.

Goligher, J. C., et al. (1968a). British Medical fournal, 2, 781.

Goligher, J. C., et al. (1968b). British Medical fournal, 2, 787.

Mead, P. H. (1967). American fournal of Surgery, 114, 910.

Price, J. J., Powis, S. J. A., and Morrissey, D. M. (1972). Submitted for publication.

Savage, L. E., and McVay, C. B. (1970). American fournal of Surgery, $119,191$. Small, W. T., and Jahadi, M. R. (1970). American fournal of Surgery,

Whittaker, L. D., Judd, E. S., and Stauffer, M. H. (1967). Surgery, Gynecology and Obstetrics with International Abstracts of Surgery, 125, 1081 .

\title{
Pernicious Anaemia and Rheumatoid Arthritis
}

\author{
H. A. GHAZI
}

British Medical fournal, 1972, 1, 144-145

\section{Summary}

In a study of 99 patients with pernicious anaemia the incidence of clinical rheumatoid arthritis was normal but rheumatoid factor was present significantly more often than in controls. This was not related to the presence of circulating antibody to intrinsic factor.

Intrinsic factor antibody was not detected in any of 151 latex-fixation-positive rheumatoid sera.

\section{Introduction}

There is probably an increased incidence of megaloblastic anaemia in rheumatoid arthritis (Chanarin, 1969). In a large retrospective survey by Partridge and Duthie (1963), involving 2,544 patients with rheumatoid arthritis and 5,515 controls, macrocytic-megaloblastic anaemia was five times more common in the rheumatoid group. This was ascribed largely to Addisonian pernicious anaemia (P.A.) by the authors. Bieder and Wigley (1964) found two cases of P.A. in a group of 20 patients with rheumatoid arthritis. But other studies by Gough et al. (1964), Deller et al. (1966), and Carter et al. (1968) did not confirm this increased frequency of P.A. in rheumatoid arthritis.

Conversely the incidence of rheumatoid arthritis in P.A. has not received much attention. Rheumatoid arthritis was not mentioned by Wilkinson (1933) in his review of diseases associated with P.A. Wangel et al. (1968) found eight patients with rheumatoid arthritis among 132 with P.A.

This report presents a study of the association of rheumatoid arthritis and P.A. and the frequency with which circulating intrinsic factor antibody and rheumatoid factor occur in the two conditions.

\section{Patients and Methods}

Table I gives the numbers and ages of patients studied. Those with P.A. were regular attenders at the haematology outpatient

Royal Infirmary, Shefield S6 3DA

H. A. GHAZI, M.B., B.S., M.R.C.P., Senior Research Registrar in Gastroenterology and Haematology department, United Sheffield Hospitals. The diagnostic criteria for P.A. included a history of megaloblastic anaemia (without previous gastric surgery) completely responding to vitamin $\mathbf{B}_{12}$ therapy, achlorhydria and/or absent or virtually absent intrinsic factor secretion on maximal gastric stimulation, and abnormal Schilling test improving significantly with a suitable dose of intrinsic factor. In each case the patient was examined by me for evidence of rheumatoid arthritis and serum tested for rheumatoid factor and intrinsic factor antibody.

TABLE I-Ages of Patients Studied

\begin{tabular}{|c|c|c|c|c|c|c|c|}
\hline & \multirow{2}{*}{\multicolumn{3}{|c|}{ No. }} & \multicolumn{4}{|c|}{ Age in Years } \\
\hline & & & & \multicolumn{2}{|c|}{ Range } & \multicolumn{2}{|c|}{ Mean } \\
\hline & Men & Women & Total & Men & Women & Men & Women \\
\hline $\begin{array}{l}\text { Pernicious anaemia } \\
\text { Latex-positive }\end{array}$ & 40 & 59 & 99 & $30-91$ & $30-85$ & $65 \cdot 2$ & $66 \cdot 2$ \\
\hline $\begin{array}{l}\text { rheumatoid arthritis } \\
\text { Controls ... }\end{array}$ & $\begin{array}{l}61 \\
87\end{array}$ & $\begin{array}{l}90 \\
95\end{array}$ & $\begin{array}{l}151 \\
182\end{array}$ & $\begin{array}{l}16-73 \\
13-92\end{array}$ & $\begin{array}{l}23-76 \\
15-92\end{array}$ & $\begin{array}{l}53.6 \\
59.7\end{array}$ & $\begin{array}{l}52 \cdot 1 \\
53 \cdot 8\end{array}$ \\
\hline
\end{tabular}

From a large number of blood samples sent for latex fixation tests to the department of haematology, United Sheffield Hospitals, 151 rheumatoid-factor-positive sera were taken. All latex-positive sera where the blood samples had been accompanied by a clinical diagnosis of rheumatoid arthritis were included in this study. The patients concerned were not examined by me. In each case the serum was tested for intrinsic factor antibody.

The 182 controls were individuals without evidence of P.A., rheumatoid arthritis, diabetes mellitus, or thyroid disease. Nearly two-thirds of these were ambulant hospital outpatients and the rest inpatients. Their sera were examined for both rheumatoid factor and intrinsic factor antibody.

Intrinsic factor antibody was detected by a modified charcoal absorption method (Ghazi, 1972) in which the amount of bound vitamin $B_{12}$ in a sequence of gastric juice (normal) $+{ }^{57} \mathrm{Co} \mathrm{B}_{12}+$ test serum is compared with that of gastric juice + test serum $+{ }^{57}$ Co $B_{12}$. Sera inhibiting $B_{12}$ uptake of gastric juice by more than $5 \mathrm{ng} / \mathrm{ml}$ were regarded as antibodypositive. Rheumatoid factor was detected by slide agglutination at serum dilutions of $1 / 25$ with human IgG-coated latex suspension (Wellcotest). 